SDNN was shift work (Beta: $-16,68 ; 95 \%$ CI: $-30,69$ to $-2,67)$.

Discussion Although Mexican healthcare professionals frequently suffer from precarious employment conditions, shift work was the main predictor for lower HRV in our study population.

\section{WORKER'S SUPPORT PROGRAM FOR URBAN VIOLENCE IN A BRAZILIAN LOGISTICS COMPANY}

${ }^{1}$ VL Zaher-Rutherford*, ${ }^{2}$ V Farias, ${ }^{2}$ FG Martins Filho. ${ }^{1}$ Faculty of Medicine, University of São Paulo, São Paulo, Brazil; ${ }^{2}$ Occupational Physician in a Logistics Company, São Paulo, Brazil

\subsection{6/oemed-2018-ICOHabstracts. 1717}

Introduction Violence in a developing country can be very common and particularly increases in an economic downturn. In a logistics company employing hundreds of drivers who sometimes face urban violence, this problem can be a great challenge for the occupational health as well as the security teams.

Methods A program to assist workers in dealing with violent incidents they encounter while working was developed in 2008. This program was developed to address legal, security, psychological, and occupational health requirements of these workers. The psychological support aspects of the program are accomplished by phone within 24 to 48 hours after the incident, with follow-ups after 15 and 30 day period.

Results Workers involved in violent incidents are provided with a company attorney when reporting the incident to the police. They also receive a phone call from a psychologist. The psychologist provides support, listening to the workers description of the incident, administering a psychological assessment, and then referring the worker for further therapy or to a psychiatrist when appropriate. Commonly, such incidents do not have physical ramifications for the worker but instead often have psychological consequences that are more difficult to measure. The same worker can experience several such assaults. Psychological issues can manifest with just one event, but there are some workers who have been involved in dozens of these events.

Discussion This support program for workers is important and necessary to help them to cope with violent incidents even when considering the ideal solution of preventing such incidents from occurring in the first place. The challenge for occupational health professionals is how to mitigate the consequences for the involved workers who are otherwise subject to potentially severe psychological and physical injuries. This program helps by opening a new communications channel and support avenue to assist the company in addressing such complex and delicate situations.

\section{LONGITUDINAL PSYCHOLOGICAL SUPPORT AFTER OCCUPATIONAL VIOLENCE IN A BRAZILIAN LOGISTICS COMPANY}

'LG Lopes, 'C Tech, 'LR Andrade, 'S Silva, 'SGB Moreira, 'V Farias, 'FG Martins Filho, 2J Silva Jr, 3,4V Zaher-Rutherford. 'Occupational Physician in a Logistics Company, São Paulo, Brazil; ${ }^{2}$ National Social Security Institute, São Paulo, Brazil; ${ }^{3}$ Agregar Consulting Practice and the; ${ }^{4}$ Faculty of Medicine, University of São Paulo, São Paulo, Brazil

\subsection{6/oemed-2018-ICOHabstracts. 1718}

Introduction Violence at work is a psychosocial risk that safety and health occupational teams have to deal with nowadays. A program to assist workers in dealing with violent incidents was developed in 2008 in a national logistics company to address legal, security, psychological, and occupational health requirements for workers. The psychological support aspects of the program are accomplished by phone within 24 to 48 hours after the incident, with follow-ups after 15 and 30 day periods. The objective of this study was to gather data relating to psychological support requirements of workers who had been victims of violent episodes in the course of their work, typically during the theft of their cargo.

Methods A longitudinal study carried out in a logistics company located in São Paulo, Brazil, during 2014-2016. Data was gathered from company notifications of violent incidents relating to theft of cargo in 5 regions of the country.

Results The average number of violent events during the three years of the study did not vary significantly from year to year and averaged 1833 events per year. The greatest frequency of events occurred during the second half of the year $(53.9 \%$ average). The regions of the country with the highest percentage of events were the southeast $(68.3 \%$ average $)$ and the least was the north $(2.3 \%$ average $)$. Requests for psychological support rose by an average of $69.0 \%$ during the study period. About $16.0 \%$ of events resulted in support requests in 2013, while $43.6 \%$ of cases generated support requests in 2016. The region generating the most psychological support requests was the southeast $(33.0 \%$ average $)$ and the least was the northeast (22.7\% average).

Discussion The data demonstrated that while the overall number of incidents remained consistent, the number of support requests from workers rose significantly during the study period. We infer from this data that the support program is viewed by the workers as being an effective tool to deal with violent incidents. It is necessary to discuss regional strategies to help increase worker use of the program. It is also recommended to analyse the impacts of violent episodes on workers and whether the psychological follow up reduces the damage to their mental and physical health.

\section{ERGONOMIC ANALYSIS OF ELECTRONIC SPORTS PLAYERS - UNRAVELLING RISKS - POST-GRADUATION IN ERGONOMICS}

${ }^{1} \mathrm{TA}$ Oliveira, ${ }^{2} \mathrm{P}$ Costa, ${ }^{3} \mathrm{HM}$ de Araújo, ${ }^{4} \mathrm{CM}$ de Toledo, ${ }^{2} \mathrm{GF}$ Primo. ${ }^{1}$ Labor Doctor, Postgraduation In Ergonomics At Senac Ribeirão Preto,Americana, Brazil; ${ }^{2}$ Physiotherapist, Postgraduation In Ergonomics At Senac Ribeirão Preto, Piracicaba, Brazil; ${ }^{3}$ Architect, Postgraduation In Ergonomics At Senac Ribeirão Preto, Ribeirão Preto, Brazil; ${ }^{4}$ Physical Education teacher, Post-graduation In Ergonomics At Senac Ribeirão Preto, Ribeirão Preto, Brazil

\subsection{6/oemed-2018-ICOHabstracts. 1719}

Introduction Performed Ergonomic Analysis of Work (AET) with professional players of Electronic Sports (mode: League of Legends). It is known through social networks, interactive newspapers and television broadcasters that the modality is on the rise and that it also brings some evidence and difficulties related to pain in the wrists of athletes.

The pains in the fist are in the area of Physical Ergonomics, but can not be considered the origin of the cause. We also know that the work tool of the players is the computer, so the second point to be studied is in the field of Cognitive Ergonomics, where we approach topics related to decision making, memory, reasoning, perception, human-machine interaction, reflexes.Ergonomics has its three established pillars: Physical, Organisational and Cognitive 